\title{
RESEARCH
}

Open Access

\section{Mass fingerprinting and electrophysiological analysis of the venom from the scorpion Centruroides hirsutipalpus (Scorpiones: Buthidae)}

Laura L. Valdez-Velázquez ${ }^{1}$, Timoteo Olamendi-Portugal ${ }^{2}$, Rita Restano-Cassulini ${ }^{2}$, Fernando Z. Zamudio and Lourival D. Possani ${ }^{2^{*}}$ (iD

\begin{abstract}
Background: Centruroides hirsutipalpus, of the family Buthidae, is a scorpion endemic to the Western Pacific region of Mexico. Although medically important, its venom has not yet been studied. Therefore, this communication aims to identify their venom components and possible functions.

Methods: Fingerprinting mass analysis of the soluble venom from this scorpion was achieved by high-performance liquid chromatography and electrospray mass spectrometry. Furthermore, the soluble venom and its toxic effects were evaluated extensively via electrophysiological assays in HEK cells expressing human voltage-gated $\mathrm{Na}^{+}$channels (hNav 1.1 to Nav1.6), CHO cells expressing hNav 1.7, potassium channel hERG 1 (Ether-à-go-go-related-gene) and the human $\mathrm{K}^{+}$-channel hKv1.1.

Results: The separation of soluble venom produced 60 fractions from which 83 distinct components were identified. The molecular mass distribution of these components varies from 340 to 21,120 Da. Most of the peptides have a molecular weight between 7001 and $8000 \mathrm{Da}$ (46\% components), a range that usually corresponds to peptides known to affect $\mathrm{Na}^{+}$ channels. Peptides with molecular masses from 3000 to $5000 \mathrm{Da}$ (28\% of the components) were identified within the range corresponding to $\mathrm{K}^{+}$-channel blocking toxins. Two peptides were obtained in pure format and completely sequenced: one with 29 amino acids, showing sequence similarity to an "orphan peptide" of C. limpidus, and the other with 65 amino acid residues shown to be an arthropod toxin (lethal to crustaceans and toxic to crickets). The electrophysiological results of the whole soluble venom show a beta type modification of the currents of channels Nav1.1, Nav1.2 and Nav1.6. The main effect observed in channels hERG and hKv 1.1 was a reduction of the currents.

Conclusion: The venom contains more than 83 distinct components, among which are peptides that affect the function of human $\mathrm{Na}^{+}$-channels and $\mathrm{K}^{+}$-channels. Two new complete amino acid sequences were determined: one an arthropod toxin, the other a peptide of unknown function.
\end{abstract}

Keywords: Centruroides, Electrophysiology, Mass fingerprinting, Scorpion venom

\footnotetext{
* Correspondence: possani@ibt.unam.mx

${ }^{2}$ Instituto de Biotecnología, Universidad Nacional Autónoma de México,

Avenida Universidad 2001, Colonia Chamilpa, apartado postal, 510-3

Cuernavaca, Morelos, Mexico

Full list of author information is available at the end of the article
}

(c) The Author(s). 2018 Open Access This article is distributed under the terms of the Creative Commons Attribution 4.0 International License (http://creativecommons.org/licenses/by/4.0/), which permits unrestricted use, distribution, and reproduction in any medium, provided you give appropriate credit to the original author(s) and the source, provide a link to the Creative Commons license, and indicate if changes were made. The Creative Commons Public Domain Dedication waiver (http://creativecommons.org/publicdomain/zero/1.0/) applies to the data made available in this article, unless otherwise stated. 


\section{Background}

Toxins from microorganisms, plants and animals are usually produced by highly specialized systems of exocrine cells or are synthesized in specific tissues of the organisms [1]. The toxins of arachnid origin, especially those from scorpions, are produced in a pair of glands located in the last segment of the metasoma, called the telson. A stinger situated at the telson tip serves as the inoculating device. The type of venom produced depends on the scorpion species, but usually the venom is neurotoxic and affects the central or peripheral nervous system of vertebrates and arthropods. The main effect is a modification of ion channel function of both excitable and non-excitable cells, often producing paralysis of the prey [2]. All scorpions are poisonous, but only a few species are extremely dangerous to humans.

In Mexico scorpions of the genus Centruroides can be lethal to humans. $\mathrm{LD}_{50}$ values in mice by subcutaneous injection can be as low as $0.075 \mu \mathrm{g} / \mathrm{g}$ body weight [3]. Originally, eight scorpion species in the country were clearly identified and reported as dangerous to humans: C. limpidus, C. noxius, C. infamatus, C. elegans, C. tecomanus, C. pallidiceps, C. sculpturatus and C. suffusus [4]. Recently, in the state of Colima, a very toxic species belonging to the family Buthidae was identified: Centruroides hirsutipalpus [5], on which no information is available concerning their venom components, structure and function. It is one of the thirteen species of dangerous scorpions now known to occur in Mexico [6].

The scorpion $C$. hirsutipalpus is endemic to this Western Pacific region of Mexico. This specie is morphologically and geographically related to two other species of "striped scorpions": C. elegans and C. tecomanus [5]. In this communication, we report the separation of its venom by chromatographic methods and identification of their molecular masses by mass spectrometry. The toxicity of the soluble venom was evaluated by electrophysiological assays and is herein reported for the first time. In addition, two interesting peptides obtained in homogeneous form were fully sequenced by Edman degradation, one with a sequence similar to an "orphan peptide" from the scorpion $C$. limpidus, while the other was shown to be an arthropod toxin lethal to crustaceans and toxic to crickets.

\section{Methods}

\section{Biological material}

The scorpion specimens were collected in the in the community of Minatitlan in the Mexican state of Colima in June 2016 (latitude $19^{\circ} 23^{\prime} 01.73^{\prime \prime} \mathrm{N}$; longitude $104^{\circ} 03^{\prime}$ 35.19' 'O; elevation $703 \mathrm{~m}$ above sea level), under an official collection permit from SEMARNAT (SGPA/ DGVS/12063/15 granted to Laura Valdez). The animals were kept in captivity (standard conditions of temperature, light and dark periods, water ad libitum and fed crickets) for 15 days. The venom was extracted from 25 scorpions via electrical stimulation (15 V shock applied to the animals), dissolved in water, centrifuged at $14,000 \mathrm{~g}$ for $15 \mathrm{~min}$; then the supernatant was immediately lyophilized and kept at $-20{ }^{\circ} \mathrm{C}$ until use.

\section{Chromatographic separation of soluble venom and mass fingerprint analysis}

The fractionation of soluble venom was performed by high performance liquid chromatography (HPLC) on an analytical $\mathrm{C} 18$ reverse-phase column (dimensions of $4.6 \times 250 \mathrm{~mm}$ ) obtained from Grace Vydac (USA). Samples of lyophilized venom ( $0.75 \mathrm{mg}$ protein content) were dissolved in $500 \mu \mathrm{L}$ of solvent A [0.12\% trifluoroacetic acid (TFA) in water] and applied to the column. Elution was obtained by running a linear gradient with solvent A (0.12\% trifluoroacetic acid in water) to $60 \%$ of solvent B $(0.10 \%$ TFA in acetonitrile), for $60 \mathrm{~min}$ at a flow rate of $1 \mathrm{~mL} / \mathrm{min}$. The protein content of the venom and fractions was estimated based on absorbance at $\lambda=280 \mathrm{~nm}$, assuming that one unit of absorbance is equal to $1 \mathrm{mg} / \mathrm{mL}$. The fractions were collected manually by monitoring the absorbance at $230 \mathrm{~nm}$ and then dried in a Savant Speed Vac SC210A apparatus (USA). The various fractions obtained from the HPLC separation were dissolved in $50 \%$ acetonitrile containing $1 \%$ acetic acid to achieve a final concentration of approximately 0.1 to $0.5 \mathrm{mg} / \mathrm{mL}$. This concentration was estimated based on the area under the curve of the various subfractions obtained from the chromatogram of the HPLC separation. All samples were analyzed using an LCQ Fleet mass spectrometer (Thermo Finnigan, USA).

\section{Primary structure determination}

Homogeneous components were submitted to Edman degradation using a PPSQ-31A protein sequencer from the company Shimadzu Scientific Instruments, Inc. (USA). When needed, the peptide was reduced and carboxymethylated for confirmation of the cysteine residues. Additionally, the alkylated peptide was enzymatically digested with Asp-N endopeptidase (Roche, Germany) for completion of the primary sequence. The latter step was performed under the same conditions already described for other toxic peptides, according to Olamendi-Portugal et al. [7].

\section{Lethality tests}

Experiments showing that this species is dangerous to humans were reported earlier by our group [6]. Herein we assayed the new purified and sequenced peptides in two additional animals: freshwater crayfish (Cambarellus montezume ssp.) and crickets (Acheta sp.), as described previously [8]. 


\section{Electrophysiological analyses}

Electrophysiological analyses of the soluble venom were performed using HEK cells expressing human voltage-gated $\mathrm{Na}^{+}$channels (hNav 1.1 to Nav1.6) and $\mathrm{CHO}$ cells expressing hNav 1.7 and potassium channels hERG 1 (Ether-à-go-go-related-gene) and hKv1.1. All cells were maintained in Dulbecco's modified Eagle medium (DMEM) (Sigma, Mexico) supplemented with $10 \%$ fetal bovine serum (FBS) (Byproductos, Mexico), at $37{ }^{\circ} \mathrm{C}$ with $5 \% \mathrm{CO}_{2}$. Antibiotic $\mathrm{G} 418$ at $400 \mu \mathrm{g} / \mathrm{mL}$ concentration was added to the medium. Cells expressing hNavs sodium channels and plasmid for hERG were kindly donated by Professor Enzo Wanke from the University of Milano Bicocca, Milan, Italy. The extracellular solution expressed in $\mathrm{mM}$ was: $130 \mathrm{NaCl}, 5 \mathrm{KCl}, 2$ $\mathrm{CaCl}_{2}, 2 \mathrm{MgCl}_{2}, 10$ HEPES and 5 glucose, at pH 7.3 adjusted with $\mathrm{NaOH}$. For hERG potassium currents, extracellular solution had $40 \mathrm{mM} \mathrm{KCl}$ and $95 \mathrm{mM} \mathrm{NaCl}$. For sodium channels records, intracellular solution contained in mM: $105 \mathrm{CsF}, 27 \mathrm{CsCl}, 5 \mathrm{NaCl}, 2 \mathrm{MgCl}_{2}$, 10 EGTA, 10 HEPES, pH 7.3 adjusted with $\mathrm{CsOH}$. For potassium channel records, the intracellular solution expressed in $\mathrm{mM}$ was: K-aspartate 130, $10 \mathrm{NaCl}, 2$ $\mathrm{MgCl}_{2}, 10 \mathrm{HEPES}$ and $10 \mathrm{EGTA}$, at pH 7.3 adjusted with $\mathrm{NaOH}$.

Sodium currents were elicited by means of a step depolarization for $100 \mathrm{~ms}$, from -120 to $40 \mathrm{mV}$ with $10 \mathrm{mV}$ increase, followed by a $50 \mathrm{~ms}$ step at full-activation potential $(-10 \mathrm{mV}$ or $-30 \mathrm{mV}$ in the case hNav 1.5 channels). The holding potential was set at -
$120 \mathrm{mV}$ and a short strong depolarization pre-pulse $(5 \mathrm{~ms}$ at $50 \mathrm{mV}$ ) was applied $50 \mathrm{~ms}$ before the depolarization steps. Potassium currents of the type $\mathrm{hKv}$ 1.1 were elicited by a step depolarization at $60 \mathrm{mV}$ for $200 \mathrm{~ms}$, followed by a step at $-50 \mathrm{mV}$ for $200 \mathrm{~ms}$. Pulses were applied every $6 \mathrm{~s}$. Currents for the hERG channel were elicited as tail currents by means of a depolarization step at $60 \mathrm{mV}$ for $500 \mathrm{~ms}$ followed by a repolarization step at $-120 \mathrm{mV}$ for $500 \mathrm{~ms}$. Pulses were applied every $6 \mathrm{~s}$. Currents were registered by means of the amplifier MultiClamp $700 \mathrm{~B}$ along with the analog-digital converter Digidata 1440A and software pCalmp10 (Molecular Devices, USA). Data were analyzed with the software Clampfit10 (Molecular Devices) and Origin 7 (OriginLab, USA).

\section{Results}

\section{HPLC separation and mass fingerprinting}

Separation of soluble venom by HPLC (Fig. 1) revealed more than 56 clear chromatographic peaks, which were collected in 60 distinct fractions. From these, at least 83 different components were identified by mass spectrometry, with molecular weights varying from 340 to 21,120 Da. The results obtained are shown in Table 1. The most abundant components found were eluted at the following retention times (RT): 20.7, 31.4, 32.5, 32.8, $33.1,33.9,34.0,34.4,34.7$ and $36.1 \mathrm{~min}$ and are shown in bold. The components of RT 20.7 and 33.9 min were sequenced as described below. All other components have molecular weights within the range of the known

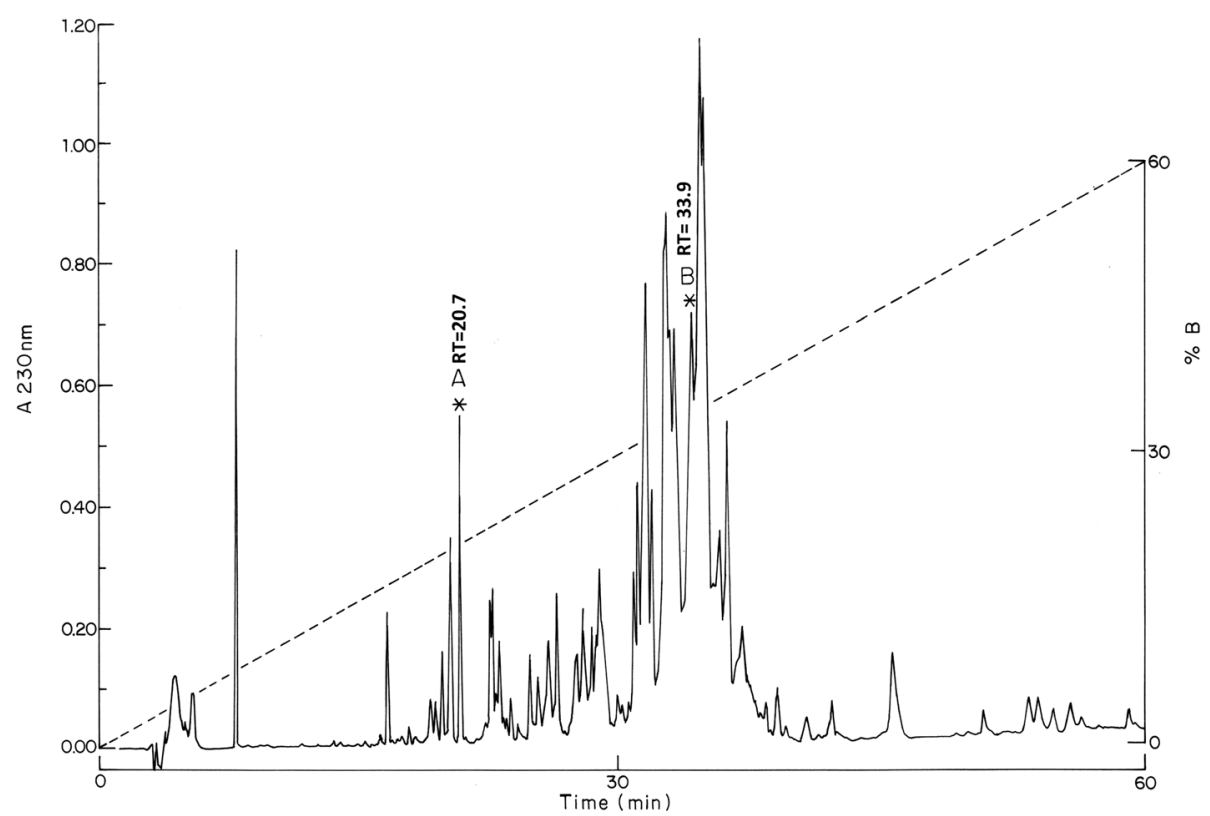

Fig. 1 Separation by HPLC of the venom of Centruroides hirsutipalpus. The soluble part of scorpion venom ( 0.75 mg of protein) was passed through a reverse phase C18 column and separated with a linear gradient of a solvent A (0.12\% trifluoroacetic acid in water) to $60 \%$ of solvent B (0.10\% TFA in acetonitrile), for $60 \mathrm{~min}$ 
Table 1 Determination of molecular weights (MW) by mass spectrometry of the venom components from C. hirsutipalpus

\begin{tabular}{|c|c|c|c|}
\hline $\mathrm{RT}$ (min) & MW (Da) & $\mathrm{RT}(\min )$ & MW (Da) \\
\hline 4.4 & ND & 29.8 & 4296.99 \\
\hline 5.1 & ND & 30.0 & $4296.9,6937.5$ \\
\hline 5.4 & ND & 30.4 & 6461 \\
\hline 7.8 & 535.3 & 30.6 & 7428.11 \\
\hline 16.6 & $2611.41,2723.94,2837$ & 30.8 & 7373.35 \\
\hline 17.4 & 492 & 31.4 & $7214,5163.79,7501.78$ \\
\hline 17.8 & 340 & 31.7 & 7422.98 \\
\hline 18.2 & 1288 & 32.5 & $7590.77,7157$ \\
\hline 19.1 & $\begin{array}{l}3665.55,4097.56 \\
2611.8\end{array}$ & 32.8 & 7591.17 \\
\hline 19.3 & $3881.16,3994.3$ & 33.1 & $7380.56,7051.53,7591$ \\
\hline 19.7 & 4325.88 & 33.9 & 7051.53 \\
\hline 20.2 & $764.67,4325.78$ & 34.0 & $7052.03,7751.45,7791.7$ \\
\hline 20.7 & 3421.84 & 34.4 & $7791.31,7299,7051.5$ \\
\hline 21.7 & 943.4 & 34.7 & $\begin{array}{l}7791.8,7462,7276.5 \\
9142\end{array}$ \\
\hline 22.2 & 2112.6 & 35.2 & 7275.29 \\
\hline 22.5 & 4123.9 & 35.7 & 7287.28 \\
\hline 22.7 & 4212.45 & 36.1 & $7169.63,7098.16$ \\
\hline 23.0 & $4039.7,4189.39,4212$ & 36.5 & $7431,7170.32,7536.07$ \\
\hline 23.4 & $4170.16,4281.63$ & 36.8 & $7170.19,7431.25$ \\
\hline 23.6 & 3982.46 & 37.4 & $7433.04,7170.2$ \\
\hline 24.1 & $3994.67,1742$ & 38.0 & $7432.41,7475.39$ \\
\hline 24.7 & 3988.18 & 38.3 & 7013.31 \\
\hline 25.2 & 4001.86 & 38.9 & $5931,7600.73$ \\
\hline 25.8 & $7765,4237.23,4084.95$ & 39.4 & 4698.84 \\
\hline 26.3 & 4775.83 & 40.6 & 7771.3 \\
\hline 27.4 & $4156.12,6963.27$ & 42.0 & $13,476.8$ \\
\hline 27.9 & $7439.89,6979.39$ & 45.5 & 21,120 \\
\hline 28.3 & 7312.05 & 51.0 & ND \\
\hline 28.7 & $6587.35,7293$ & 53.9 & ND \\
\hline 29.0 & 6587 & 55.7 & ND \\
\hline
\end{tabular}

Bold numbers means more abundants components

$\mathrm{Na}^{+}$-channel toxins. A few components (total 6) were not identified, either due to their chemical compositions or complexity (several components in the fractions, impeding individual bona fide identification). Please note that a few components with identical masses separated at different eluting times of the HPLC.

The molecular mass distribution of the venom components found in the 60 fractions are displayed in Fig. 2 clustered within different intervals of molecular weights, mostly $1000 \mathrm{Da}$ apart from each other. Four groups of components with distinct molecular masses were found: $<500-1000$ Da (5.6\%), 1001-5000 Da (36\%), 5001-
$9000 \mathrm{Da}(55 \%)$ and $9001-30,000 \mathrm{Da}(3.4 \%)$. The majority of peptides have a molecular weight of 4001 to $5000 \mathrm{Da}$ or from 7001 to $8000 \mathrm{Da}$, ranges that usually correspond to peptides known to affect $\mathrm{K}+$ channels and $\mathrm{Na}+$ channels, respectively.

\section{Primary structure determination}

Subfractions eluted at $20.7 \mathrm{~min}$ and $33.9 \mathrm{~min}$, labeled A and B, respectively, in Fig. 1, were shown to be homogeneous by mass spectrometry and were used for determination of their primary structures. Figure 3 shows the primary structure of these peptides. Peptide A was sequenced automatically by Edman degradation. This peptide has a molecular weight of $3421.84 \mathrm{Da}$ and contains 29 amino acids, among which are six cysteines that form three disulfide bonds. After reduction and alkylation, the full amino acid sequence was obtained. Peptide B has molecular weight of $7051.53 \mathrm{Da}$ and contains 65 amino acids, including eight cysteines that form four disulfide bonds. The first 52 amino acids at the N-terminal region were identified directly by Edman degradation. An overlapping segment at the C-terminal section, residues 48 to 65 , was identified after reduction, carboxymethylation and digestion with endopeptidase Asp N. This toxin fragment was separated by HPLC eluting at 23.4 min (data not shown).

The two new peptides sequenced and reported herein are very interesting peptides as will be discussed later. One was $97 \%$ identical to CllNtx, a peptide of undetermined function [9], whereas the other was shown to be an arthropod toxin. Each of four crayfish and four crickets was injected with $50 \mu \mathrm{g}$ of this peptide. All animals were paralyzed immediately after injection. The effect was more pronounced in crayfish, which became paralyzed for at least $8 \mathrm{~h}$. One of them died within the first $24 \mathrm{~h}$; the other three recovered. The crickets were transiently paralyzed, surviving the injection.

\section{Electrophysiological analyses}

The effects of the $\mathrm{C}$. hirsutipalpus-soluble venoms were analyzed at $20 \mu \mathrm{g} / \mathrm{mL}$ concentration, on seven subtypes of human sodium channels (hNav 1.1-1.7) and two sub-types of $\mathrm{K}+$ channels (hKv1.1 and hERG).

Venom application to the sodium channel produced modification in the voltage dependence of the activation process. This effect, which is typical of scorpion beta toxins, was evident on hNav 1.1, hNav 1.2 and on hNav 1.6 subtypes (Fig. 4, panels a, b and f). In these channels, especially in hNav 1.6, venom induced activation at more negative potential and reduction of peak current (Fig. 4, panels a, b and f). By contrast, hNav 1.3, hNav 1.4, hNav 1.5 and hNav 1.7 were insensitive to venom at the used concentration (Fig. 4, panels c, d, e and g). None of the sodium channels in analysis showed any 


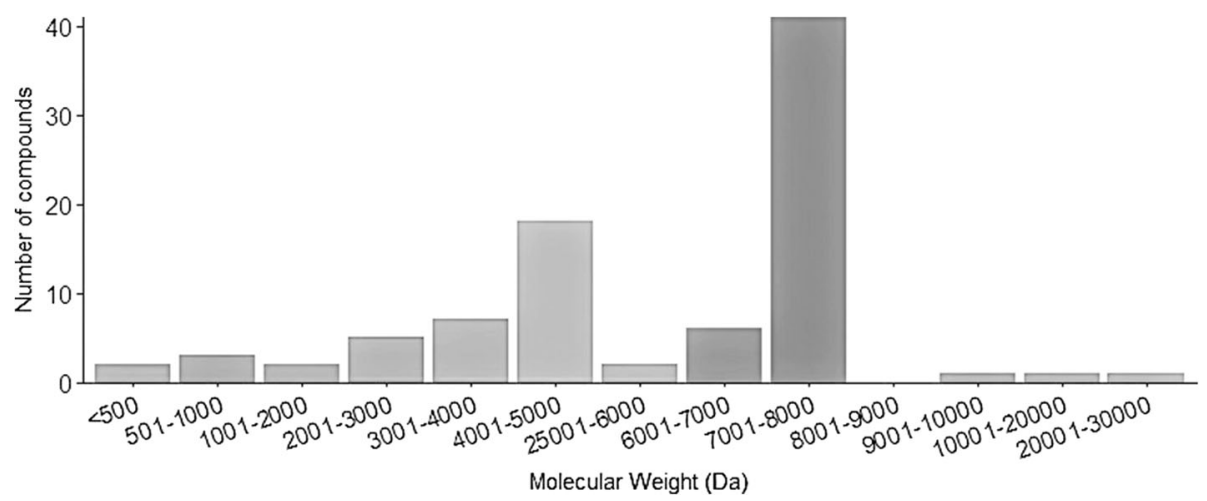

Fig. 2 Fingerprinting of soluble venom. The histogram shows the frequency distribution of molecular weights (MW), in Da, for the 89 peptide masses determined (from which 83 were distinct), present in the venom of Centruroides hirsutipalpus, clustered within different intervals of molecular weights (1000 Da apart from each other). The MWs were obtained using the mass spectrometer LCQ Fleet

change in the inactivation process after venom application (Fig. 4, panels a-g).

Venom was also able to reduce currents of the voltage-gated potassium channels hKv 1.1 and hERG, when applied at $20 \mu \mathrm{g} / \mathrm{mL}$ concentration. In both cases, venom action was reversible (Fig. 4, panels $\mathrm{h}$ and $\mathrm{i}$, respectively). Current values were plotted against time; then data were fitted with an exponential equation to extrapolate the onand off-kinetic time constants (Ton and Toff, respectively). In Fig. 4, panel (h) and (i) the grey line is the best fit for on-kinetic data and light grey line is the best fit for off-kinetic data fitting. The resulting time constants were for hERG1: Ton $9.4 \mathrm{~s}$ and Toff $27.4 \mathrm{~s}$; for $\mathrm{hKv}$ 1.1: Ton $32 \mathrm{~s}$ and Toff $77 \mathrm{~s}$. Based on the equation:

$$
\mathrm{KD}=\frac{\text { Ton }[\mathrm{V}]}{(\text { Toff }- \text { Ton })}
$$

the apparent venom concentration that produced a half effect (KD) was estimated at $10 \mu \mathrm{g} / \mathrm{mL}$ for $\mathrm{hKv} 1.1$ and $14 \mu \mathrm{g} / \mathrm{mL}$ for hHERG1 (venom concentration [V] was $20 \mu \mathrm{g} / \mathrm{mL}$ ). In Table 2, we summarize the data obtained for activation and inactivation of the channels, under the effect of the whole soluble venom.

\section{Discussion}

In Mexico, approximately 300,000 people per year are reported as having been stung by a scorpion. Clinical application of a commercially available horse antivenom has reduced the deadly cases to less than 100 persons yearly [10]. The Centruroides hirsutipalpus scorpion is endemic in Minatitlan, a small area in the state of Colima with 8985 inhabitans, in which 176 cases of human envenomation by this scorpion have been reorted. Thus far, no data concerning the venom composition of this scorpion species or its effects are available. This communication reports the HPLC separation of its soluble venom, the determination of the molecular weight of the main components as determined by mass spectrometry analysis, as well the electrophysiological effects of the soluble venom on various types of ion channels, known to be the target of scorpion toxins.

The physiological effects of these venom components produce an abnormal massive depolarization of the target cells causing impairment of their proper function [11]. We report herein that the venom of $C$. hirsutipalpus is a complex mixture containing at least 83 different components. Since this venom might also contain protease enzymes, it is possible that some of the peptides identified by mass

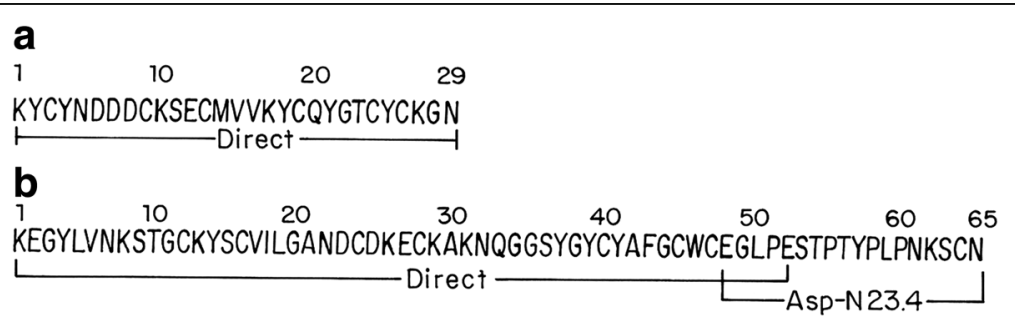

Fig. 3 Primary structure of purified peptides. (a) Peptide with molecular weight 3421.84 Da, containing 29 amino acids. Captioned "Direct" means sequence obtained directly by automatic Edman degradation. (b) Peptide of 7051.53 Da containing 65 amino acids and sequenced directly by Edman degradation, and completed by sequencing the peptide "Asp N 23.4" obtained after enzymatic digestion of a reduced and alkylated sample 


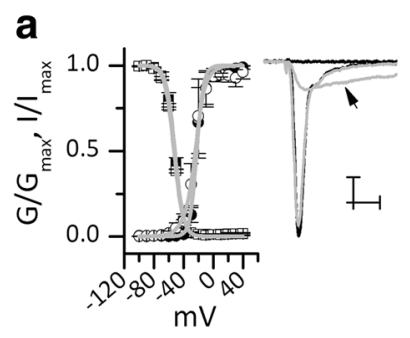

d

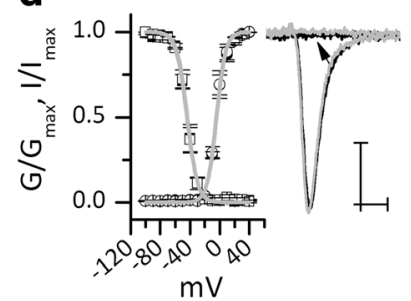

g

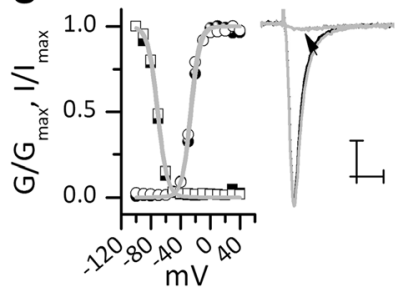

b

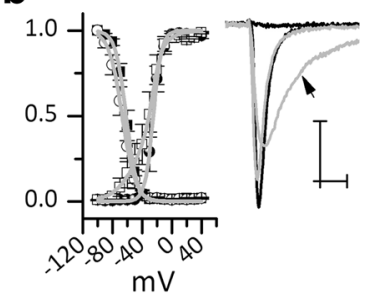

e

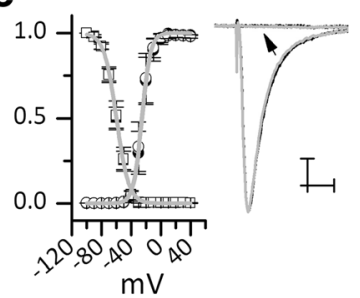

h

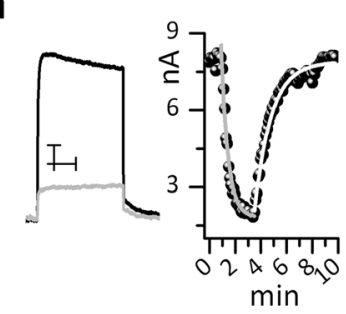

C

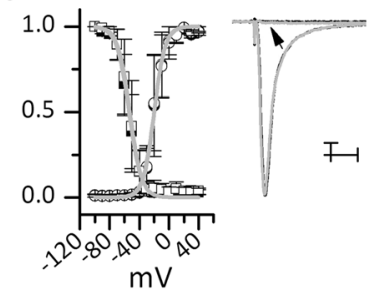

$\mathbf{f}$

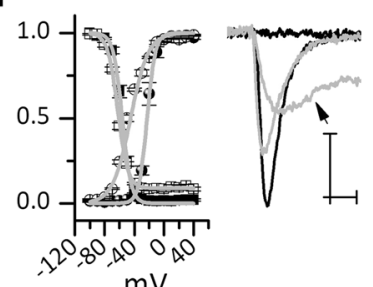

i

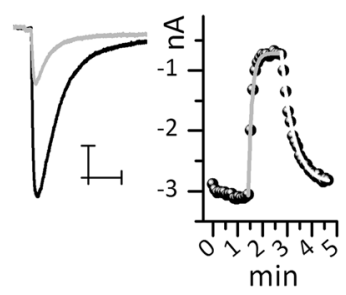

Fig. 4 Electrophysiological characterization of soluble venom. The effect of soluble Centruroides hirsutipalpus venom on sodium and potassium ion channels. From panels A to G: sodium currents of hNav 1.1 to 1.7 channels, respectively. On the right side of each panel are represented the current traces elicited with stimulus at - $10 \mathrm{mv}$ (maximal current) and at - $50 \mathrm{mv}$ (sub-threshold stimulus). Black lines are for control and grey lines are for venom application. In (a) hNav 1.1, (b) hNav 1.2 and (f) hNav 1.6, venom produced current at - $50 \mathrm{mV}$ (arrow) and reduction of the maximal current. The (c) hNav 1.3, (d) hNav 1.4, (e) hNav 1.5 and (g) hNav 1.7 were insensitive to the venom. In each panel, on the left, are represented the activation (circlet) and the inactivation (squares) curves. Full symbols are for the control and empty symbols are for the venom. Grey line are the best fit from a Boltzmann equation or the sum of two Boltzmann equations. In (a), (b) and (f) venom moves activation curve to more negative potentials. (h) Venom produced current reduction on hKv 1.1 channels. The left side shows current in control (black line) and after venom application (grey line). On the right, current values were plotted against time and data were fitted with a first-order exponential equation. Grey line is the best fit of the on-kinetic data and light gray line is the best fit of the off-kinetic data. (i) Venom produced current reduction on hERG1 channels. The left side shows current in control (black line) and after venom application (grey line). On the right, current values were plotted against time and data were fitted with a first-order exponential equation. Grey line is the best fit of the on-kinetic data and light gray line is the best fit of the off-kinetic data. Scaler is $1 \mathrm{~ms}$ and $1 \mathrm{nA}$ in panels $(\mathbf{a}),(\mathbf{b}),(\mathbf{c}),(\mathbf{e}),(\mathbf{g}) ; 1 \mathrm{~ms}$ and $0.5 \mathrm{nA}$ in panels $(\mathbf{d}),(\mathbf{f}) ; 50 \mathrm{~ms}$ and $1 \mathrm{nA}$ in panels (h) and (i)

spectrometry are produced by enzymatic cleavage of original peptides/proteins. However, as mentioned in Table 1, a few fractions were not identified (ND) by mass spectrometry. Usually this is due to proteins (mainly enzymes of higher molecular weight, as discussed in [12]) that cannot be identified by the mass spectrometer we used. Thus, the suggestion that this venom contains at least 80 distinct components is reasonable. The majority of peptides have a molecular weight ranging from 7001 to 8000 (46\% components fall in this category) as shown in Fig. 2, which usually corresponds to peptides known to affect $\mathrm{Na}^{+}$-channels.

From the medical point of view, the sodium-channel-specific toxins are the most important ones. They usually are polypeptides with a length of 61-76 amino acids, folded with four disulfide bonds [13]. Particularly in this species a large number of components having a molecular mass similar to
Table 2 Activation and inactivation V1/2 values

\begin{tabular}{|c|c|c|c|c|}
\hline \multirow{2}{*}{$\begin{array}{l}\text { Sodium } \\
\text { channel }\end{array}$} & \multicolumn{2}{|c|}{$V_{1 / 2}$ activation $(\mathrm{mV})$} & \multicolumn{2}{|c|}{$V_{1 / 2}$ inactivation $(\mathrm{mV})$} \\
\hline & Control & Venom & Control & Venom \\
\hline hNav 1.1 & $-22.4 \pm 0.5$ & $-26.5 \pm 3.4$ & $-52 \pm 0.2$ & 0.2 \\
\hline Nav 1.2 & $-25 \pm 0.3$ & $-43 \pm 3$ & $-61.6 \pm 0.2$ & $-66.9 \pm 0.3$ \\
\hline nav 1.3 & $-20 \pm 0.6$ & $-19.9 \pm 0.5$ & $-53.9 \pm 0.5$ & $-52.6 \pm 0.6$ \\
\hline hNav 1.4 & $-4.2 \pm 0.4$ & $-4.4 \pm 0.4$ & $-43.8 \pm 0.3$ & $-44.2 \pm 1.4$ \\
\hline hNav 1.5 & $-25.7 \pm 0.3$ & $-25 \pm 0.3$ & $-59.7 \pm 0.3$ & $60 \pm 0.3$ \\
\hline hNav 1.6 & $-22.8 \pm 0.3$ & $-45.2 \pm 1$ & $-56.4 \pm 0.3$ & $-62.3 \pm 0.2$ \\
\hline Nav 1.7 & $-25.7 \pm 0.3$ & $-27 \pm 0.4$ & $-71.5 \pm 0.4$ & $70.6 \pm 0.3$ \\
\hline
\end{tabular}

$\mathrm{V}_{1 / 2}=$ middle activation or inactivation potential 
the sodium-channel-specific toxins were found. Approximately $33 \%$ of the peptides found in another phylogenetically related scorpion species occurring in Colima (Centruroides tecomanus) corresponded to toxins with this molecular weight [14]. In some other scorpions of the same genus, such as Centruroides noxius, the most poisonous not only in Mexico but also in the world, seven toxins are known to be specific to mammals [15]. The electrophysiological analysis of C. hirsutipalpus venom shows an effect on the channels Nav 1.1, 1.2 and 1.6. The current modification produced by this venom is described as a beta effect, which means channel activation at a more negative potential and gradual decrease of the peak current [16-18].

In addition to the sodium toxins, the molecules that are also responsible for the toxicity of the venom are peptides in the range of molecular masses from 3000 to $5000 \mathrm{Da}$, which are $\mathrm{K}^{+}$-channel blockers $(28 \%$ of these are listed, see Table 1) [13-19]. The effect on hERG and hKv 1.1 channels is displayed in Fig. 4; the currents were reduced with soluble Centruroides hirsutipalpus venom.

As we stated previously, the newly sequenced peptides are very interesting given their high similarity to other known peptides isolated from the venom of various Centruroides species. Peptide A of Fig. 1 is $97 \%$ identical to a peptide (CllNtx). This peptide was assayed for various possible functions, such as mouse and insect toxicity, antimicrobial activity and $\mathrm{K}^{+}$-channel-blocking effects, all of which were negative and presented no effects. Thus far, it is considered to be an "orphan peptide" [8], whereas peptide B in Fig. 1 is $89 \%$ identical to $\mathrm{Cn} 5$, an arthropod toxin found to be identical in two different scorpion species (C. noxius and $C$. suffusus suffusus). $\mathrm{Cn} 5$ is toxic to crustaceans and its three-dimensional structure was determined [20]. Thus, the results reported herein are original data that confirm similar findings in related species of Mexican scorpions.

This communication contributes to the knowledge on the toxicity of the species Centruroides hirsutipalpus, which may in the future improve current antivenoms by investigating targets for toxins from this species that have not yet been evaluated.

\section{Conclusion}

In conclusion, this work reports the fingerprinting mass of components from the venom of Centruroides hirsutipalpus, finding a predominance of toxins specific to sodium or potassium channels, as shown in the mass fingerprinting of the soluble venom. Two new peptides were fully sequenced. One was classified as "orphan peptide" of unknown function and the other peptide as an arthropod toxin. The whole soluble venom is demonstrated to affect Nav channels 1.1, 1.2 and 1.6, and potassium channels hERG and hKv 1.1 .

\section{Abbreviations}

DMEM: Dulbecco's modified Eagle medium; FBS: fetal bovine serum; HPLC: high performance liquid chromatography; MW: molecular weight; ND: not identified; RT: retention times; TFA: trifluoroacetic acid

\section{Acknowledgements \\ The authors are grateful to the students of the School of Chemical Sciences, University of Colima, who supported the collection of specimens. The authors thank Professor Enzo Wanke from University of Milano Bicocca, Milan, Italy, for the gift of cells expressing hNavs sodium channels and plasmid for hERG. The graphical support of Mr. Pedro Saucedo is acknowledged and appreciated.}

\section{Ethical approval}

The protocol used in the present study was approved by the Institutional Committee for Animal Welfare. The scorpion specimens were collected under an official collection permit from SEMARNAT (SGPA/DGVS/12063/15 granted to Laura Valdez).

\section{Funding}

This study was partially supported by grants SEP-CONACyT 237864 and IN203416 of DGAPA-UNAM to LDP.

Availability of data and materials

All data generated or analyzed during this study are included in this published article.

\section{Authors' contributions}

LLW collected the venom, helped perform HPLC separation, conceived and analyzed the data, and helped write the main core of the manuscript. TOP performed the separation of components of the scorpion venom with HPLC. RRC performed and data analyzed the electrophysiological assays. FZZ performed electrospray mass spectrometry analysis. LDP helped to design the experiments, analyze data and write the manuscript. Grants given to his laboratory partially supported the experiments done. All authors read and approved the final manuscript.

Consent for publication

Not applicable.

Competing interests

The authors declare that they have no competing interests.

\section{Publisher's Note}

Springer Nature remains neutral with regard to jurisdictional claims in published maps and institutional affiliations.

\section{Author details}

${ }^{1}$ Facultad de Ciencias Químicas, Universidad de Colima, Coquimatlan, Colima, Mexico. ${ }^{2}$ Instituto de Biotecnología, Universidad Nacional Autónoma de México, Avenida Universidad 2001, Colonia Chamilpa, apartado postal, 510-3 Cuernavaca, Morelos, Mexico.

Received: 8 March 2018 Accepted: 14 June 2018

Published online: 03 July 2018

\section{References}

1. Zhang L, Shi W, Zeng XC, Ge F, Yang M, Nie Y, et al. Unique diversity of the venom peptides from the scorpion Androctonus bicolor revealed by transcriptomic and proteomic analysis. J Proteome. 2015;128:231-50.

2. Possani LD, Merino E, Corona M, Bolivar F, Becerril B. Peptides and genes coding for scorpion toxins that affect ion-channels. Biochimie. 2000:82(9-10):861-8.

3. Kouznetsov V: Kalium. Defensa química en la naturaleza. http://kaliumdb. org. Accessed 18 Jul 2017

4. Dehesa-Dávila M, Possani LD. Scorpionism and serotherapy in Mexico. Toxicon. 1994;32(9):1015-8.

5. Ponce-Saavedra J, Francke OF. Descripción de una especie nueva de alacrán con importancia médica del género Centruroides (Scorpiones: Buthidae) del estado de Colima. México Rev Mex Biodiv. 2009;80(3):647-58. 
6. Riaño-Umbarila L, Rodríguez-Rodríguez ER, Santibañez-López CE, Güereca L, Uribe-Romero SJ, Gómez-Ramírez IV, et al. Updating knowledge on new medically important scorpion species in Mexico. Toxicon. 2017;138:130-7.

7. Olamendi-Portugal $T$, Restano-Cassulini R, Riaño-Umbarila L, Becerril B, Possani LD. Functional and immuno-reactive characterization of a previously undescribed peptide from the venom of the scorpion Centruroides limpidus. Peptides. 2017;87:34-40.

8. Lebreton F, Delepierre M, Ramírez AN, Balderas C, Possani LD. Primary and NMR three-dimensional structure determination of a novel crustacean toxin from the venom of the scorpion Centruroides limpidus limpidus Karsch. Biochemistry. 1994;33(37):11135-49.

9. Cid Uribe Jl, Jiménez Vargas JM, Ferreira Batista CV, Zamudio Zuñiga F, Possani LD. Comparative proteomic analysis of female and male venoms from the Mexican scorpion Centruroides limpidus: novel components found. Toxicon. 2017:125:91-8.

10. Chávez-Haro AL, Ortiz E. Scorpionism and dangerous species of Mexico.In Gopalakrishnacoke P, Possani LD, Schwartz EF, Rodriguez de la Vega RC editors. Scorpion Venoms. Dordrecht: Springer; 2015. p201-213.

11. Catterall WA, Cestèle S, Yarov-Yarovoy V, Yu FH, Konoki K, Scheuer T. Voltage-gated ion channels and gating modifier toxins. Toxicon. 2007; 49(2):124-41.

12. Batista CVF, del Pozo L, Zamudio FZ, Contreras S, Becerril B, Wanke E, et al, Proteomics of the venom from the Amazonian scorpion Tityus cambridgei and the role of prolines on mass spectrometry analysis of toxins. J Chromatogr B Analyt Technol Biomed Life Sci. 2004;803(1):55-66.

13. Possani LD, Becerril B, Delepierre M, Tytgat J. Scorpion toxins specific for $\mathrm{Na}$ +-channels. Eur J Biochem. 1999;264(2):287-300.

14. Valdez-Velázquez LL, Quintero-Hernández V, Romero-Gutiérrez MT, Coronas FI, Possani LD. Mass fingerprinting of the venom and transcriptome of venom gland of scorpion Centruroides tecomanus. PLoS One. 2013;8(6): e66486.

15. Quintero-Hernández V, Jiménez-Vargas JM, Gurrola GB, Valdivia HH, Possani LD. Scorpion venom components that affect ion-channels function. Toxicon. 2013;76:328-42.

16. Cestèle S, Qu Y, Rogers JC, Rochat H, Scheuer T, Catterall WA. Voltage sensor-trapping: enhanced activation of sodium channels by beta-scorpion toxin bound to the S3-S4 loop in domain II. Neuron. 1998:21(4):919-31.

17. Cestèle S, Scheuer T, Mantegazza M, Rochat H, Catterall WA. Neutralization of gating charges in domain II of the sodium channel alpha subunit enhances voltage-sensor trapping by a beta-scorpion toxin. J Gen Physiol. 2001;118(3):291-302.

18. Cestèle S, Yarov-Yarovoy V, Qu Y, Sampieri F, Scheuer T, Catterall WA. Structure and function of the voltage sensor of sodium channels probed by a beta-scorpion toxin. J Biol Chem. 2006;281(30):21332-44.

19. Possani,LD: Structure of scorpion toxins. In Tu AT, editor. Handbook of natural toxins, vol.2. New York: Marcel Dekker, Inc. 1984. p513-550

20. Corzo G, Prochnicka-Chalufour A, García BI, Possani LD, Delepierre M Solution structure of $\mathrm{Cn} 5$, a crustacean toxin found in the venom of the scorpions Centruroides noxius and Centruroides suffusus suffusus. Biochim Biophys Acta. 2009;1794(11):1591-8

\section{Ready to submit your research? Choose BMC and benefit from:}

- fast, convenient online submission

- thorough peer review by experienced researchers in your field

- rapid publication on acceptance

- support for research data, including large and complex data types

- gold Open Access which fosters wider collaboration and increased citations

- maximum visibility for your research: over $100 \mathrm{M}$ website views per year

At BMC, research is always in progress.

Learn more biomedcentral.com/submissions 